\title{
Clinical Utility and Approach to Estimate Postprandial Hypertriglycemia by A Newly Designed Oral Fat-loading Test
}

\author{
Masahiko Igarashi ${ }^{1,3}$, Akihiko Hirata ${ }^{1}$, Toshiyuki Yamauchi², Hiroshi Yamaguchi ${ }^{3}$, \\ Hiromi Tsuchiya ${ }^{3}$, Hiroshi Ohnuma ${ }^{3}$, Yumi Jimbu ${ }^{3}$, Yoko Okuyama ${ }^{4}$, Toru Shirata ${ }^{4}$, \\ Nobuhiro Otsu4, Haru Fukuyama ${ }^{4}$, Sachiko Takahashi², Makoto Tominaga ${ }^{1}$, and \\ Takeo Kato ${ }^{3}$ \\ ${ }^{1}$ Department of Laboratory Medicine, \\ ${ }^{2}$ Division of Nutrition Management, \\ ${ }^{3}$ Third Department of Internal Medicine, \\ ${ }^{4}$ Division of Clinical Laboratory, Yamagata University School of Medicine, Yamagata, Japan.
}

\begin{abstract}
The objective of this study was to estimate postprandial hypertriglycemia by a newly designed oral fat-loading test. Twenty-three healthy normolipidemic volunteers were orally administered a test meal consisting of a mixture of Telmeal $2.0^{\circledR}$ and $20 \mathrm{~g}$ of saltfree butter after fasting for $\mathbf{1 2} \mathrm{h}$. To measure the levels of total cholesterol (T-Cho), triglycerides (TG), high-density lipoprotein-cholesterol (HDL-C), remnant-like particlecholesterol (RLP-C), lipoprotein (a) [Lp (a)], free fatty acid, apolipoproteins (Apos), plasma glucose (PG), immunoreactive insulin (IRI), and high-sensitivity C-reactive protein (hs-CRP), venous blood samples were collected before the meal and at each hour until $9 \mathrm{~h}$ after fat-loading. The levels of both TG and RLP-C were drastically elevated at $2 \mathrm{~h}$ after fat-loading and these levels remained high until $4 \mathrm{~h}(p<0.01)$. A significant correlation between TG and RLP-C was also observed at 2, 3 and $4 \mathrm{~h}$, and the values of the correlation coefficients ( $r$ ) were $0.837,0.838$, and 0.908 , respectively. In contrast, the levels of T-Cho, HDL-C, Lp (a), Apos, PG, and hs-CRP did not change. Furthermore, there were no gastrointestinal symptoms during or after the study. These results strongly suggested that this newly designed fat-loading test was very useful for evaluating postprandial hypertriglycemia, including remnant concentrations. $J$ Atheroscler Thromb, 2003; 10: 314-320.
\end{abstract}

Key words: Fat-loading test; Triglycerides; Remnant-like particle-cholesterol; Telmeal ${ }^{\circledR}$

\section{Introduction}

Multiple epidemiological and clinical studies have established that dyslipidemia, e.g., increased total cholesterol (T-Cho), particularly low-density lipoprotein-cholesterol (LDL-C), and decreased high-density lipoproteincholesterol (HDL-C), is the most crucial factor in the pathogenesis of atherosclerosis, including coronary heart

Address for correspondence: Masahiko Igarashi, Department of Laboratory Medicine, Yamagata University School of Medicine, 2-2-2, lida-nishi, Yamagata 990-9585, Japan.

E-mail: migarasi@med.id.yamagata-u.ac.jp

Received June 16, 2003.

Accepted for publication June 24, 2003. disease (CHD) and subsequent sudden death (1-5). In contrast, although some investigators have reported that moderately elevated fasting triglycerides (TG) increased coronary events (6-9), the independent role of TG in the contribution of $\mathrm{CHD}$ has been controversial, since the fasting level of TG is inversely related to that of HDL-C in lipid metabolism (10). Most studies on the relationship between atherosclerosis and lipids have been based on fasting lipid levels.

Recently, however, some prospective studies have clearly shown the potential importance of postprandial hypertriglycemia in the etiology of $\mathrm{CHD}$ even after adjusting for HDL-C using multivariate analyses $(11,12)$. Iso et al. have demonstrated that the nonfasting serum 
TG level could predict the incidence of CHD, even in Japanese subjects who showed a decreased level of T-Cho, followed over a 15.5-year period (11). Talmud et al. have also suggested that the combined evaluation of apolipoprotein (Apo) B with nonfasting TG could provide useful diagnostic criteria for CHD risk (12). In addition, considerable evidence supports the view that postprandial hypertriglycemia is associated with insulin resistance, its concomitant compensatory hyperinsulinemia, and obesity $(13,14)$.

In contrast, although several investigators have tried and reported fat-loading tests to examine postprandial hypertriglycemia in recent years (14-19), the evaluation and/or standardization of the test has not been fully established since neither the amount nor the type of lipids has been determined. Indeed, although some, but not all, reports on the fat-loading test might be available, the fact that trials have been conducted using different methods has made it difficult to compare the results for postprandial hypertriglycemia. Some proposed oral fat-loading tests were more complicated since the test meals were composed of a mixture of four to nine types of food $(14-17,19)$. In addition, these fat-loading tests have brought about more serious problems, such as excessive loading of calories and an imblance in the energy ratio (14-18). The likely reason for these problems is that rapidly-introlerable lipid absorption by the test meals used led to subsequent gastrointestinal symptoms such as abdominal discomfort and diarrhea.

We believe that better and more comfortable oral fatloading tests, such as the $75 \mathrm{~g}$ oral glucose-tolerance test, are called for to evaluate and standardize postprandial hypertriglycemia. Therefore, in this study, we designed a simple oral fat-loading test meal for the estimation of postprandial hypertriglycemia and evaluated its usefulness.

\section{Research Design and Methods}

\section{Subjects}

A total of 23 healthy normolipidemic volunteers were recruited among the students of the Yamagata University School of Medicine, and informed consent was obtained from the participants. Their mean age was $24.0 \pm$ 0.5 , and the sex ratio (male/female) was 15/8. Their height and body weight were determined to calculate their body mass index (BMI). Laboratory samples were obtained in the morning, and the following information was determined: fasting plasma glucose (FPG), serum levels of immunoreactive insulin (IRI), total cholesterol (T-Cho), triglycerides (TG), high-density lipoprotein-cholesterol (HDL-C), remnant-like particle-cholesterol (RLP-C), lipoprotein (a) [Lp (a)], free fatty acid (FFA), high-sensitivity C-reactive protein (hs-CRP), lipoprotein lipase (LPL), cholesterol ester transfer protein (CETP), and apolipoproteins (Apos) such as A-I, A-II, B, C-II, C-III and $E$. The details of the clinical characteristics of the subjects are summarized in Table 1. There were not any abnormal findings in the laboratory parameters of the subjects.

This study was approved by the ethical committee of the Yamagata University School of Medicine.

\section{Protocol for the oral fat-loading test}

The test meal was made with a mixture of Telmeal $2.0^{\otimes}$ (Telmo, Tokyo, Japan), a commercially-available enteral nutrition drink that has $400 \mathrm{kcal} / 200 \mathrm{ml}$, and $20 \mathrm{~g}$ of saltfree butter (Table 2). The total volume of the test meal was almost $200 \mathrm{ml}$, and the combined amounts of fat and energy were $31.6 \mathrm{~g}$ and $553 \mathrm{kcal}$, respectively. After fasting for $12 \mathrm{~h}$, a venous blood sample was collected for the measurement of basal laboratory parameters. The test meal was then orally administered, and venous blood samples were collected every hour until $9 \mathrm{~h}$ after the beginning of fat-loading. The blood samples were immediately centrifuged at $1,500 \times \mathrm{g}$ for $15 \mathrm{~min}$, and the plasma and sera were harvested and stored for the measurement of laboratory parameters. During the fat-loading test, the subjects were prohibited from exercising and additional eating but they were permitted to drink water.

Table 1. Clinical characteristics of 23 healthy volunteers included in this study.

\begin{tabular}{|c|c|c|c|}
\hline Age (Year) & $24.0 \pm 0.5$ & FFA (mEq/l) & $0.68 \pm 0.06$ \\
\hline $\begin{array}{l}\text { Gender } \\
\text { (Male/Female) }\end{array}$ & $15 / 8$ & $\begin{array}{l}\text { hs-CRP } \\
\text { (mg/dl) }\end{array}$ & $0.021 \pm 0.004$ \\
\hline BMI $\left(\mathrm{kg} / \mathrm{m}^{2}\right)$ & $21.0 \pm 0.5$ & LPL (ng/ml) & $211.5 \pm 10.9$ \\
\hline FPG (mg/dl) & $90.0 \pm 1.4$ & CETP $(\mu \mathrm{g} / \mathrm{ml})$ & $1.8 \pm 0.06$ \\
\hline $\mathrm{IRI}(\mu \mathrm{U} / \mathrm{ml})$ & $8.9 \pm 0.7$ & Apo A-I (mg/dl) 1 & $154.3 \pm 4.8$ \\
\hline T-Cho (mg/dl) & $174.4 \pm 4.9$ & Apo A-II (mg/dl) & $29.5 \pm 0.8$ \\
\hline $\mathrm{TG}(\mathrm{mg} / \mathrm{dl})$ & $81.6 \pm 5.9$ & Apo B (mg/dl) & $69.1 \pm 3.3$ \\
\hline HDL-C (mg/dl) & $67.8 \pm 3.0$ & Apo C-II (mg/dl) & $3.0 \pm 0.2$ \\
\hline RLP-C (mg/dl) & $3.6 \pm 0.3$ & Apo C-III (mg/dl) & $8.5 \pm 0.4$ \\
\hline Lp (a) (mg/dl) & $16.1 \pm 3.2$ & Apo E (mg/dl) & $3.8 \pm 0.2$ \\
\hline
\end{tabular}

Data are the mean $\pm \operatorname{SEM}(n=23)$.

Table 2. Composition of the oral fat-loading test meal in this study.

\begin{tabular}{cccrcc}
\hline Contents & $\begin{array}{c}\text { Weight } \\
(\mathrm{g})\end{array}$ & $\begin{array}{r}\text { Energy } \\
(\mathrm{kcal})\end{array}$ & $\begin{array}{r}\text { Protein } \\
(\mathrm{g})\end{array}$ & \multicolumn{1}{c}{$\begin{array}{c}\text { Fat } \\
(\mathrm{g})\end{array}$} & $\begin{array}{c}\text { Carbohydrate } \\
(\mathrm{g})\end{array}$ \\
\hline Telmeal 2.0 & 200 & 400 & 14.5 & 15.0 & 52.0 \\
Salt-free butter & 20 & 153 & 0.1 & 16.6 & 0 \\
\hline Sum & 220 & 553 & 14.6 & 31.6 & 52.0 \\
\hline
\end{tabular}




\section{Measurement of laboratory parameters}

The serum levels of T-Cho, TG and FFA were determined by an enzymatic method, and that of high-density lipoprotein-cholesterol (HDL-C) by a precipitation method. In addition, measurements of RLP-C and Lp (a) were performed by an immunosorbent assay (20) and a latex agglutinative turbidimetric immunoassay, respectively. The levels of FPG and IRI were measured by a glucose oxidase and enzymatic immunoassay, respectively. Hs-CRP was measured by a particle-enhanced immunonephrometric assay (21), and all types of Apos were quantified by a turbidimetric immunoassay. In addition, the measurements of LPL and CETP were conducted by the enzyme-linked immunosorbent assay in a commercial laboratory (SRL, Tokyo, Japan).

\section{Statistical analysis}

The results were expressed as mean \pm SEM. The statistical significance was estimated by one-way-analysis of variance (ANOVA) for the comparison and/or linear regression analyses for the correlation of the parameters, and the difference was considered to be significant at $p<0.05$.

\section{Results}

\section{Changes of serum levels of T-Cho, TG, and HDL-C}

As shown in Fig. 1, the levels of T-Cho and HDL-C were not changed by the fat-loading test, suggesting that temporary fat-load did not affect metabolism. However, in a comparison of the basal value, the level of TG was significantly elevated to $134.0 \pm 11.2 \mathrm{mg} / \mathrm{dl}$ at $2 \mathrm{~h}$ after fatloading and reached a maximum, which was $180 \%$ of the basal level, at $3 \mathrm{~h}$. The significant elevation of TG was prolonged until $4 \mathrm{~h}$ after fat-loading and gradually declined, indicating that this fat-loading meal could be useful for estimating postprandial hypertriglycemia.

\section{Changes of serum levels of RLP-C and FFA}

Similar to the changes of TG, the level of RLP-C was significantly elevated to $5.77 \pm 0.48 \mathrm{mg} / \mathrm{dl}$ at $2 \mathrm{~h}$ after fat-loading and reached a maximum, which was $184 \%$ of the basal level, at $3 \mathrm{~h}$ (Fig. 2). The significant elevation of TG was prolonged until $4 \mathrm{~h}$ after fat-loading and gradually declined to the basal level. In contrast, inverse to the change of RLP-C, the level of FFA was significantly decreased by fat-loading but gradually increased in response to starvation after fat-loading.

\section{Changes of plasma glucose and IRI}

Since this test meal contained $52 \mathrm{~g}$ of carbohydrate, we further examined the changes in the levels of plasma glucose and IRI after the oral fat-loading test in 23 healthy normolipidemic volunteers. As shown in Fig. 3, the level

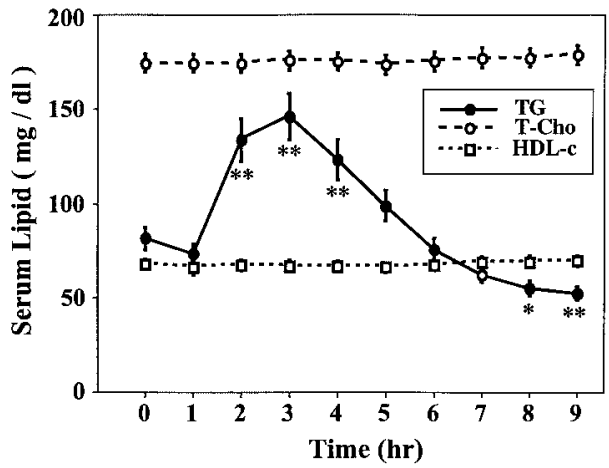

Fig. 1. Changes in the levels of serum lipids (T-Cho, TG, and HDL-C) after the oral fat-loading test in 23 healthy normolipidemic volunteers. All data are expressed as the mean \pm SEM $(n=23)$. Blood samples were collected before and after fat-loading at each hour until 9 . $* p<0.05, * * p<0.01 \mathrm{vs}$. Time 0 in TG.

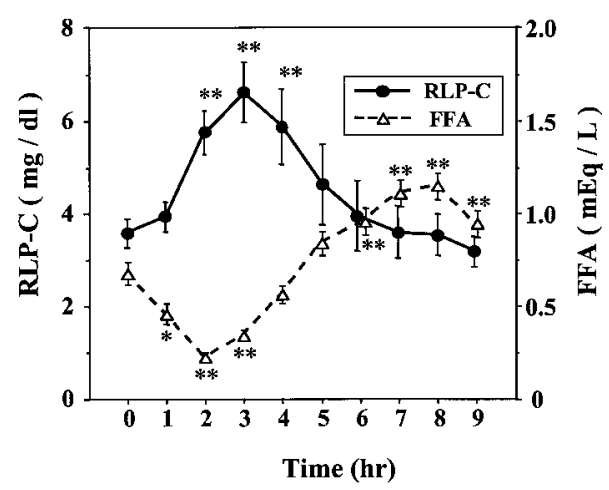

Fig. 2. Changes in the levels of RLP-C and FFA after the oral fat-loading test in 23 healthy normolipidemic volunteers. All data are expressed as the mean \pm SEM $(n=23)$. Blood samples were collected before and after fat-loading at each hour until 9. $* p<0.05, * * p<0.01$ vs. respective Time 0 .

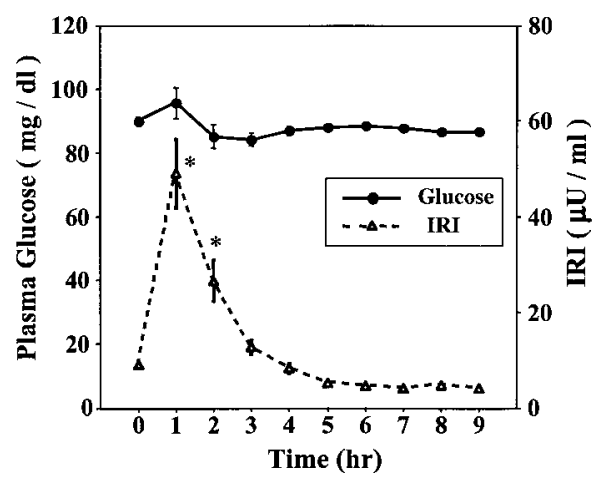

Fig. 3. Changes in the levels of plasma glucose and IRI after the oral fat-loading test in 23 healthy normolipidemic volunteers. All data are expressed as the mean \pm SEM $(n=23)$. Blood samples were collected before and after fat-loading at each hour until 9 . $* p<0.01 \mathrm{vs}$. Time 0 in IRI. 
of plasma glucose was slightly elevated at $1 \mathrm{~h}$ after fatloading but immediately declined and reached a plateau at under $90 \mathrm{mg} / \mathrm{dl}$ after $2 \mathrm{~h}$. In contrast, the level of IRI was remarkably increased at $1 \mathrm{~h}$ after fat-loading and gradually declined until $3 \mathrm{~h}$.

\section{Relationship between TG and RLP-C}

To further clarify the clinical identity between TG and $R L P-C$ in the fat-loading test, we examined the relationship between the serum values of TG and RLP-C. Interestingly, each value of RLP-C from 0 to $9 \mathrm{~h}$ was significantly correlated with those of TG in the participants of this study [correlation coefficient $(R)=0.850, p<0.001$ ] (Fig. 4). In addition, a significant correlation between TG and RLP-C was also observed at 2, 3 and $4 \mathrm{~h}$, and these values of $R$ were $0.837,0.838$, and 0.908 , respectively $(p<0.001)$ (Fig. 5).

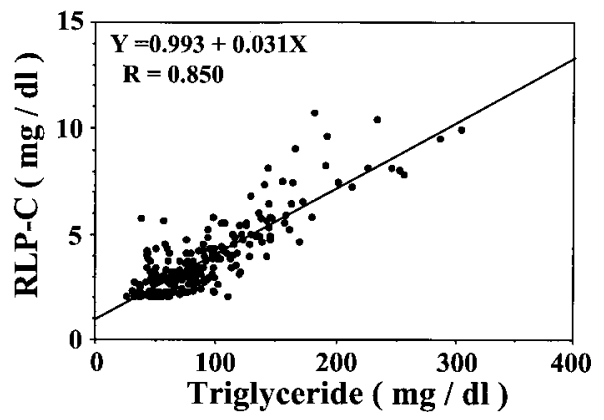

Fig. 4. Correleation between the levels of triglycerides and RLP$\mathrm{C}$ at each hour before and after oral fat-loading in 23 healthy normolipidemic volunteers $(n=230)$.
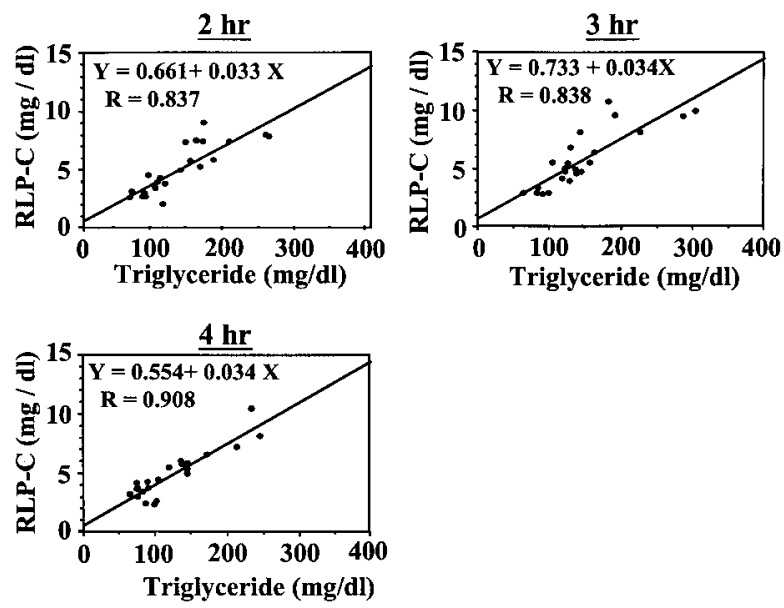

Fig. 5. Correlation between the levels of triglycerides and RLP$\mathrm{C}$ at 2,3 , and $4 \mathrm{~h}$ after oral fat-loading in 23 healthy normolipidemic volunteers $(n=23)$.

\section{Other assessments}

Although we examined the change of Lp (a), Apos, and hs-CRP in this fat-loading test, no change was observed by the test meal (data not shown). The levels of LPL and CETP were within normal ranges in all of the participants.

In addition, there were no gastrointestinal symptoms, such as nausea, vomiting, and/or diarrhea during or after this study. All of the participants easily drank the fatloading test meal and, in their opinion, the test meal was similar to a vanilla milkshake.

\section{Discussion}

Several investigators have suggested that postprandial lipoprotein metabolism is a critical and initiating factor in the development of atherosclerosis including CHD (11, $12,22,23)$. Iso et al. have shown that nonfasting TG values were significantly associated with the incidence of $\mathrm{CHD}$, even though the levels of T-Cho were not so high compared with those indicated in most of the epidemiological and clinical studies (11). Talmud et al. have suggested that the combined evaluations of TG with Apo B could be useful diagnostic criteria for CHD (12). These reports strongly suggested that postprandial hypertriglycemia could be potentially atherogenic. In contrast, Jeppesen et al. have reported that relative risk of CHD was more elevated in groups with mid-range and highest-third TG levels in comparison with those with lower-third TG levels, after multiple adjustment including HDL-C and LDL-C (24). Couch et al. have demonstrated that the postprandial level of TG was more accurate for the prediction of fasting TG level, even in children, by the estimation of the incremental area under the postprandial TG responsive curve (25). Indeed, since the serum level of TG can vary widely by daily energy intake, even in healthy individuals, and the level in hyperlipidemic and diabetic patients can be more elevated, it is likely that a significant change in TG could contribute to the progression of atherosclerosis.

Recently, RLP-C has been demonstrated as a independent risk factor of $\mathrm{CHD}$ and implicated in the progression of atherosclerosis (26-28). RLP-C is a TG-rich lipoprotein, and the compositional characteristics are interestingly similar to those of postprandially-modified verylow-density lipoprotein (VLDL) and chylomicron remnants (20). Since remnants such as RLP-C are easily accumulated by macrophages, subsequently leading to the production of foam cells in the arterial walls, this type of lipoprotein is atherogenic $(29,30)$.

To evaluate and standardize the postprandial changes of TG and/or RLP-C, a number of the oral fat-loading tests have been previously designed and reported (14$19,31)$. In the initial fat-loading studies, some protocols required that the participants ingest a fat-rich shake, usually similar to cream, and the amount was often more 
than $100 \mathrm{~g}$ of fat per dose $(14,19)$. Recent studies have used more suitable fat levels in their test meal $(15,18$, 31). However, the compositions were still complicated.

In the present study, we proposed a simple oral fatloading test meal for the estimation of postprandial hypertriglycemia and could clearly demonstrate that the serum levels of both TG and RLP-C were rapidly elevated after $2 \mathrm{~h}$ by only $31.6 \mathrm{~g}$ of fat. In addition, a significant relationship between pstprandial levels of both TG and RLP-C was also obtained at 2, 3 and $4 \mathrm{~h}$ after fat-loading. These favorable results suggest that this newly designed fat-loading test was very useful for evaluating postprandial hypertriglycemia, including remnant concentrations.

In the beginning of the study, we designed a simple oral fat-loading test meal by using a mixture of Telmeal $2.0^{\circledR}$ and $20 \mathrm{~g}$ of salt-free butter. Telmeal $2.0^{\circledR}$ is a commercially-available tube-feeding drink containing 400 $\mathrm{kcal} / 200 \mathrm{ml}$ with $14.5 \mathrm{~g}$ of protein, $15 \mathrm{~g}$ of fat, and $52 \mathrm{~g}$ of carbohydrate. It is commonly administered to patients after a gastrointestinal and/or neurosurgical operation in Japan. Since the amount of fat in Telmeal $2.0^{\circledR}$ was considered insufficient for the elevation of serum lipid levels, we initially added various volumes of salt-free butter from $10 \mathrm{~g}$ to $50 \mathrm{~g}$ to the enteral nutrition drink for the evaluation of tolerability. We thus determined that $20 \mathrm{~g}$ of butter, subsequently $31.6 \mathrm{~g}$ of fat, was absolutely tolerable for all of the participants. Indeed, although the oral bolus infusion was assumed to be intolerable, Mattes has shown that butter, but not other fat compounds, was suitable for the estimation of postprandial hypertriglycemia (32).

Based on the preliminarily evaluation of the test meal, we next examined the response of lipids after fat-loading. As shown in Fig. 1, we demonstrated that, compared with the basal value, the level of TG was significantly elevated after $2 \mathrm{~h}$ of fat-loading and continued for $4 \mathrm{~h}$, indicating that this fat-loading test meal could be useful for estimating postprandial hypertriglycemia. In contrast, as in other reports $(14,19)$, the levels of neither T-Cho nor HDL-C changed, even as a result of the transient fatloading in this study.

Similar to the levels of TG, the levels of RLP-C were also significantly elevated at $2 \mathrm{~h}$ after fat-loading and these increases continued for $4 \mathrm{~h}$ (Fig. 2). These findings were more immediate, even with the small amount of fat used, when compared with those of other fat-loading tests reported previously $(18,31)$. Those fat-loading tests utilized $70 \mathrm{~g}$ of fat, a much larger amount than that included in our study. Therefore, it is reasonable to assume that the fat-loading test meal could be more rapidly absorbable than the previously-proposed test meals, since the levels of IRI were also drastically elevated in response to fat-loading (Fig. 3). In contrast, Pedersen et al. have reported that the addition of $50 \mathrm{~g}$ of glucose to a meal significantly reduced the lipidemic response of that meal relative to a meal without glucose (33). Indeed, although the present test meal included $52 \mathrm{~g}$ of carbohydrates, the discrepancy might be due to methodological differences, since the compositions of the meals, including their adapted oils, were quite diverse and complicated. As for the change of FFA, as in another report (14), the levels were temporarily decreased by fat-loading and gradually increased, which could be considered a physiological response because the changes of IRI were automatically diverse (Fig. 3).

Furthermore, we evaluated the relationship between TG and RLP-C levels after this fat-loading test. Interestingly, as shown in Fig. 4, each RLP-C value from 0 to $9 \mathrm{~h}$ was significantly correlated with those of TG in the participants of this study [correlation coefficient $(R)=0.850, p$ $<0.001]$. In addition, a significant correlation between TG and RLP-C was also observed at 2, 3, and $4 \mathrm{~h}$, and the values of $R$ were $0.837,0.838$, and 0.908 , respectively $(p<0.001)$ (Fig. 5). These results strongly suggested that the levels of postprandial TG were absolutely associated with those of RLP-C. Several investigators have shown that the serum levels of both TG and RLP-C are high in patients with hyperlipidemia and type-2 diabetes $(20,31,34)$. Therefore, these findings may support the possibility that this newly designed fat-loading test is very useful for evaluating postprandial hypertriglycemia, including remnant concentrations in patients with insulin resistance.

In this study, however, we did not obtain a significant change in Apos (data not shown). Some reports have shown that the changes in TG were related to those of Apos $(14,35)$. Although the precise mechanism remains unclear, it is likely that the discrepancy may result from the different types of test meal, including the loading calories, composition, and/or amount of fat. For example, Guerci et al. administered $890 \mathrm{kcal}$ of energy from a blended emulsified meal to participants (14), and Waterworth et al. adopted a fat meal consisting of 1,493 $\mathrm{kcal}$ of energy including milk fat. These two meals were completely different from those used in this newly designed fat-loading test.

In conclusion, in this study, we established that our newly designed fat-loading test could be very useful for evaluating not only postprandial hypertriglycemia but also postprandial elevation of RLP-C. Theses results provide a new insight into the potential significance of the estimation of postprandial hypertriglycemia, for example, in patients with metabolic syndrome, which may have clinical benefits and contribute to the prevention of atherosclerosis.

\section{References}

(1) Kannel WB, Castelli WP, Gordon T, and McNamara 
PM: Serum cholesterol, lipoproteins, and the risk of coronary heart disease. The Framingham study. Ann Intern Med, 74: 1-12, 1971

(2) Stamler J, Wentworth D, and Neaton JD: Is relationship between serum cholesterol and risk of premature death from coronary heart disease continuous and graded? Findings in 356,222 primary screeners of the Multiple Risk Factor Intervention Trial (MRFIT). JAMA, 256: 2823-2828, 1986

( 3 ) Gordon DJ, Probstfield JL, Garrison RJ, Neaton JD, Castelli WP, Knoke JD, Jacobs DR Jr, Bangdiwala $\mathrm{S}$, and Tyroler HA: High-density lipoprotein cholesterol and cardio-vascular disease. Four prospective American studies. Circulation, 79: 8-15, 1989

(4) Stampfer MJ, Coliditz GA, Willett WC, Manson JE, Rosner B, Speizer FE, and Hennekens CH: Postmenopausal estrogen therapy and cardiovascular disease. Ten-year follow-up from the nurses' health study. N Engl J Med, 325: 756-762, 1991

( 5 ) Smith GD, Shipley MJ, Marmot MG, and Rose G: Plasma cholesterol concentration and mortality. The Whitehall Study. JAMA, 267: 20-76, 1992

( 6 ) Manninen V, Tenkanen L, Koskinen P, Huttunen JK, Manttari M, Heinonen OP, and Frick MH: Joint effects of serum triglycerides and LDL cholesterol and HDL cholesterol concentrations on coronary heart disease risk in the Helsinki Heart Study. Implications for treatment. Circulation, 85: 37-45, 1992

( 7 ) Assmann G and Schulte H: Relation of high-density lipoprotein cholesterol and triglycerides to incidence of atherosclerotic coronary artery disease (the PROCAM experience). Am J Cardiol, 70: 733-737, 1992

( 8 ) Hidis HN, Mack WJ, Azen SP, Alaupovic P, Pogoda JM, LaBree L, Hemphill LC, Kramsch DM, and Blankenhorn DH: Triglyceride- and cholesterol-rich lipoproteins have a differential effect on $\mathrm{mild} / \mathrm{mod}-$ erate and severe lesion progression as assessed by quantitative coronary angiography in a controlled trial of lovastatin. Circulation, 90: 42-49, 1994

( 9 ) Hokanson JE and Austin MA: Plasma triglycerides level is a risk factor for cardiovascular disease independent of high-density lipoprotein cholesterol level: a meta-analysis of population-based prospective studies. J Cardiovasc Risk, 3: 213-219, 1996

(10) Eisenberg S: High density lipoprotein metabolism. J Lipid Res, 25: 1017-1058, 1984

(11) Iso $H$, Naito $Y$, Sato $S$. Kitamura A, Okamura T, Sankai T, Shimamoto T, lida M, and Komachi Y: Serum triglycerides and risk of coronary heart disease among Japanese men and women.Am J Epidemiol, 153: 490-499, 2001

(12) Talmud PJ, Hawe E, Miller GJ, and Humphries SE: Nonfasting apolipoprotein $B$ and triglyceride levels as a useful predictor of coronary heart disease risk in middle-aged UK men. Arterioscler Thromb Vasc Biol, 22: 1918-1923, 2002

(13) Taira K, Hikita M, Kobayashi J, Bujo H, Takahashi K, Murano S, Morisaki N, and Saito Y: Delayed postprandial lipid metabolism in subjects with intra-abdominal visceral fat accumulation. Eur J Clin Invest, 29: 301-308, 1999

(14) Guerci B, Verges B, Durlach V, Hadjadj S, Drouin $\mathrm{P}$, and Paul JL: Relationship between altered postprandial lipemia and insulin resistance in normolipidemic and normoglucose tolerant obese patients. Int J Obes, 24: 468-478, 2000

(15) Schrezenmeir J, Keppler I, Fenselau S, Weber P, Biesalski HK, Probst R, Laue CH, Zuchhold HD, Prellwitz W, and Beyer J: The phenomenon of a high triglycerides response to an oral lipid load in healthy subjects and its link to the metabolic syndrome. Ann NY Acad Sci, 683: 302-314, 1993

(16) Uiterwaal CSPM, Grobbee DE, Witteman JCM, van Stiphout WHJ, Krauss XH, Havekes LM, de Brujin AM, van Tol A, and Hofman A: Postprandial triglyceride response in young adult men and familial risk for coronary atherosclerosis. Ann Intern Med, 121: 576-583, 1994

(17) Reznik Y, Pousse P, Herrou M, Morello R, Mahoudeau J, Drosdowsky MA, and Frandin S: Postprandial lipoprotein metabolism in normotriglyceridemic non-insulin-dependent diabetic patients: Influence of apolipoprotein E polymorphism. Metabolism, 45: 63-71, 1996

(18) Tanaka A, Tomie N, Nakano T, Nakajima K, Yui K, Tamura M, and Numano F: Measurement of postprandial remnant-like particles (RLPs) following a fat-loading test. Clin Chim Acta, 275: 43-52, 1998

(19) Karpe F, Hellenius M, and Hamsten A: Differences in postprandial concentrations of very-low-density lipoprotein and chylomicron remnants between triglyceridemic and hypertriglyceridemic men with and without coronary heart disease. Metabolism, 48: 301-307, 1999

(20) Nakajima K, Saito T, Tamura A, Suzuki M, Nakano T, Adachi M, Tanaka A, Tada N, Nakamura H, Campos $\mathrm{E}$, and Havel RJ: Cholesterol in remnant-like lipoproteins in human serum using monoclonal anti apo B-100 and anti A-I immunoaffinity mixed gels. Clin Chim Acta, 223: 53-71, 1993

(21) Ledue TB, Weiner DL, Sipe JD, Poulin SE, Collins $\mathrm{MF}$, and Rifai N: Analytical evaluation of particleenhanced immunonepherometric assays for C-reactive protein, serum amyloid $A$ and mannose-binding protein in human serum. Ann Clin Biochem, 35: 745-753, 1998

(22) Roche HM and Gibney MJ: The impact of postprandial lipemia in accelerating atherothrombosis. $J$ Cardiol Risk, 7: 317-324, 2000 
(23) Sniderman AD: Postprandial hypertriglycemia (s): Time to enlarge our pathophysiolgic perspective. Eur J Clin Invest, 30: 935-937, 2000

(24) Jeppesen J, Hein HO, Suadicani P, and Gyntelberg $\mathrm{F}$ : Triglyceride concentration and ischemic heart disease: An eight-year follow-up in the Copenhagen Male Study. Circulation, 97: 1029-1036, 1998

(25) Couch SC, Isasi CR, Karmally W, Blaner WS, Starc TJ, Kaluski D, Deckelbaum RJ, Ginsberg HN, Shea $\mathrm{S}$, and Berglund L: Predictors of postprandial triacylglycerol response in children: The Columbia University Biomarkers Study. Am J Clin Nutr, 72: 1119-1127, 2000

(26) Devaraj S, Vega G, Lange R, Grundy SM, and Jialal I: Remnant-like particle cholesterol levels in patients with dysbetalipoproteinemia or coronary artery disease. Am J Med, 104: 445-450, 1998

(27) Karpe F, Taskinen MR, Nieman MS, Frick MH, Kesaniemi YA, Pasternack A, Hamsten A, and Syvanne M: Remnant-like lipoprotein particle cholesterol concentration and progression of coronary and vein-graft atherosclerosis in response to gemfibrozil treatment. Atherosclerosis, 157: 181187, 2001

(28) McNamara JR, Shah PK, Nakajima K, Cupples LA, Wilson PW, Ordovas JM, and Schaefer EJ: Remnant-like particle (RLP) cholesterol is an independent cardiovascular disease risk factor in women: Result from the Framingham Heart Study. Atherosclerosis, 154: 229-236, 2001
(29) Phillips NR, Waters D, and Havel RJ: Plasma lipoproteins and progression of coronary artery disease evaluated by angiography and clinical events. Circulation, 88: 2762-2770, 1993

(30) Havel RJ: Postprandial hyperlipidemia and remnant lipoproteins. Curr Opin Lipidol, 5: 102-109, 1994

(31) Ai M, Tanaka A, Ogita K, Sekine M, Numano F, Numano F, and Reaven GM: Relationship between plasma insulin concentration and plasma remnant lipoprotein response to an oral fat load in patients with type 2 diabetes. J Am Coll Cardiol, 38: 16281632, 2001

(32) Mattes RD: Oral exposure to butter, but not fat replacers elevates postprandial triacylglycerol concentration in humans. J Nutr, 131: 1491-1496, 2001

(33) Pedersen A, Marckmann P, and Sandstrom B: Postprandial lipoprotein, glucose and insulin response after two consecutive meals containing rapeseed oil, sunflower oil or palm oil with or without glucose at the first meal. Br J Nutr, 82: 97-104, 1999

(34) Tomono S, Kawazu S, Kato N, Ono T, Ishii C, Ito Y, Shimizu M, Shimoyana M, Nakano T, and Nakajima $\mathrm{K}$ : Uptake of remnant like particles (RLP) in diabetic patients from mouse peritoneal macrophages. $J$ Atheroscler Thromb 1: 98-102, 1994

(35) Waterworth DM, Ribalta J, Nicaud V, Dallongeville $J$, Humphries SE, and Tamlud $P$, on behalf of the EARS Group: ApoCIII gene variants modulate postprandial response to both glucose and fat tolerance test. Circulation, 99: 1872-1877, 1999 